\title{
Necessidade hídrica da cultura do girassol irrigado na chapada do Apodi
}

\author{
Edmilson G. C. Junior', José F. de Medeiros', Talyana K. de Melo², \\ José Espinola Sobrinho ${ }^{1}$, Gilmar Bristot ${ }^{3}$ \& Bruno M. de Almeida ${ }^{4}$
}

\begin{abstract}
RESUMO
A cultura do girassol vem sendo utilizada nos últimos anos pelos produtores do Rio Grande do Norte, após o aumento de demanda devido ao Programa Nacional de Produção e Uso do Biodiesel (PNPB). De vez que se trata de uma cultura sem tradição na região não existem, para ela, estudos sobre o manejo de água; portanto, este trabalho teve por objetivo determinar a evapotranspiração da cultura e os coeficientes de cultivo para os diferentes estádios de desenvolvimento do girassol, cultivar Catissol I, na Chapada do Apodi, RN. A medição diária da evapotranspiração da cultura (ETc) foi realizada utilizando-se dois lisímetros de pesagem idênticos, com área útil de $2,7 \mathrm{~m}^{2}$. A evapotranspiração de referência (ETo) foi estimada pelo método Penman-Monteith parametrizado pela FAO. O ciclo da cultura foi de 90 dias e os totais de ETc e ETo ocorridos durante este período foram, respectivamente, 442,0 e 580,6 mm. A duração das fases fenológicas foram definidas em 28, 15, 27 e 20 dias de duração para a fase inicial (Fase I) de desenvolvimento vegetativo (Fase II), floração (Fase III) e maturação fisiológica (Fase IV) respectivamente. Os coeficientes de cultivo obtidos para os diferentes estádios de desenvolvimento foram de 0,52, 0,74, 0,98 e 0,81 para as respectivas fases I, II, III e IV.
\end{abstract}

Palavras-chave: manejo de irrigação, lisímetro de pesagem, evapotranspiração

\section{Water requirement of irrigated sunflower in the Plateau of Apodi - Brazil}

\begin{abstract}
Sunflower (Helianthus annuus L.) crop has been cultivated during the last years by the producers in Rio Grande do Norte, after the increase in demand due to National Program for Production and Use of Biodiesel. Being a non traditional crop in the region, there are no studies about the water management, so this work aimed to determine the crop evapotranspiration (ETC) and the crop coefficients (Kc) for the different development stages of the sunflower, cultivar Catissol I, in the plateau of Apodi - RN. Daily measurements of ETc were performed using two similar weighing lysimeters, with useful area of $2.7 \mathrm{~m}^{2}$. The reference evapotranspiration (ETo) was estimated using the method of Penman-Monteith FAO.The crop cycle was of 90 days and the total ETC and ETo during this period were, respectively, 442.0 and 580.6 $\mathrm{mm}$. The phenological stages were defined with the duration of 28, 15, 27 and 20 days for the initial phase (Phase I), vegetative development (Phase II), flowering (Phase III) and physiological maturation (Phase IV), respectively. The crop coefficients obtained for the different stages of development were $0.52,0.74,0.98$ and 0.81 for the phases I, II, III and IV, respectively.
\end{abstract}

Key words: irrigation management, weighing lysimeter, evapotranspiration

DCA/UFERSA. C.P. 137, CEP 59625-900, Mossoró, RN. Fone: (84) 9654-6853. E-mail: ediguatu@yahoo.com.br; jfmedeir@ufersa.edu.br; jespinola@ufersa@edu.br

${ }^{2}$ Instituto de Defesa e Inspeção Agropecuária do Rio Grande do Norte, Rua Aureliano Lopo, S/N, Centro, CEP 59650-000, Assú, RN. Fone: (84) 9946-9594. E-mail: talyanakadja@hotmail.com

${ }^{3}$ Empresa de Pesquisa Agropecuária do Rio Grande do Norte, Av. Eliza Branco Pereira dos Santos, s/n - Parques das Nações, Parnamirim, RN. Fone: (84) 3232-5864. E-mail: gilmar-emparn@rn.gov.br

${ }^{4}$ ESALQ/USP, Av. Pádua Dias, 11, CEP 13418-900, Piracicaba, SP. Fone: (88) 9631-2119. E-mail: brunomarcal@usp.br 


\section{INTRODUÇÃO}

Com grande parte de seu território inserida em clima semiárido, a região Nordeste, em particular o estado do Rio Grande do Norte, convive com características climáticas bastante peculiares, onde quadros de estiagem são bastante frequentes, uma vez que o período chuvoso se restringe ao primeiro semestre.O déficit hídrico na região pode chegar a até $800 \mathrm{~mm} \mathrm{ano}^{-1}$, tornando a irrigação peça fundamental para a produção agrícola.

A baixa sensibilidade fotoperiódica da planta de girassol permite que seu cultivo possa ser realizado durante todo o ano, em todas as regiões produtoras de grãos. Porém altas temperaturas do ar verificadas nos períodos de florescimento, enchimento de aquênios e de colheita, têm sido um dos maiores condicionantes para o sucesso da exploração agrícola (Leiteet al., 2007). Além disso e devido às características de resistência à seca, ao frio e ao calor, o girassol apresenta ampla adaptabilidade proporcionando perspectivas para a expansão de sua área cultivada em diversas regiões do Brasil (Morais et al., 2011). A produção nacional do girassol alcançou, em 2010,o total de 84700 toneladas, segundo dados do Instituto Brasileiro de Geografia e Estatística.

Nos últimos anos a cultura do girassol vem sendo cultivada pelos produtores do RN, no período chuvoso, em rotação com o melão irrigado e sob irrigação no período seco, após a demanda devido ao Programa Nacional de Produção e Uso do Biodiesel (PNPB) que visa aumentar a produção de biodiesel nacional a partir de diferentes fontes oleaginosas. Sendo uma cultura sem tradição na região, não existem estudos sobre o manejo de água para a mesma, o que tornou necessário a realização de pesquisas que visem auxiliar os produtores da região em resposta a esta questão.

A determinação precisa da evapotranspiração da cultura $(\mathrm{ETc})$ é de grande importância para o uso eficiente da água, principalmente em regiões áridas e semiáridas (Figueirêdo et al., 2009). A medição da variação de peso de um bloco de solo isolado (lisímetro de pesagem) é considerada um dos métodos de pesquisa mais práticos e precisos para se determinar diretamente a evapotranspiração das culturas podendo ser utilizada para períodos de tempo menores que um dia (Howellet al., 1985). Os lisímetros, desde que bem instalados e manejados, são as ferramentas mais precisas para reproduzir as condições reais de campo (Looset al., 2007). Pereira et al. (2002) comentaram que tais estruturas se justificam apenas em condições experimentais pois se trata de um método trabalhoso e caro, o que inviabiliza sua utilização para o simples manejo de irrigação em pequenas propriedades rurais.

Lisímetros de pesagem determinam diretamente a evapotranspiração pelo balanço de massa de água, ao contrário dos lisímetros não-pesáveis, que a determinam indiretamente pelo balanço de volume. Há vários tipos de lisímetros, sendo que o tamanho e o projeto de montagem de cada um depende do requerimento específico do estudo e das condições de construção e de custos envolvidos (Silva et al., 1999). A lisimetria de pesagem vem sendo utilizada como técnica padrão na determinação da evapotranspiração de cultura e de referência em vários trabalhos encontrados na literatura
(Miranda et al., 2004; López-Urrea et al., 2006; Vaughan et al., 2007).

$\mathrm{Na}$ ausência de equipamentos de medida direta de evapotranspiração da cultura, os pesquisadores lançam mão, muitas vezes, de estimativas baseadas na evapotranspiração de referência (ETo) e do coeficiente indicativo da necessidade de água da cultura $(\mathrm{Kc})$ em cada um de seus estádios de desenvolvimento (Doorenbos \& Pruitt (1977). Inúmeros são os métodos de estimativa da ETo, alguns dos quais têm aceitação quase que unânime, enquanto outros são bastante criticados e até desprezados (Pereira \& Allen, 1997). A conveniência para utilizar um ou outro método depende de uma série de fatores, como: a disponibilidade de dados meteorológicos, a escala de tempo requerida e a adaptabilidade do método à região de estudo. Por isto se observou a necessidade de obter um método padrão que se adaptasse a diferentes localidades e climas; com este objetivou-se realizar modificações no método PenmanMonteith (Allen et al. 2006).

Os dados de Kc apresentados na literatura podem servir de referencial quando não houver dados locais na região em que a cultura está instalada. No entanto, a estimativa de Kc, para as condições reais da área em que a cultura está implantada, é desejável em razão das variabilidades climáticas e diferentes práticas agronômicas adotadas em cada região (Pereira \& Allen, 1997). Logo, estudos são necessários para que se possa determinar a quantidade de água a ser aplicada em uma cultura para que só então ela produza satisfatoriamente com o menor consumo de água e energia possíveis. Este trabalho teve como objetivo determinar a necessidade hídrica real da cultura do girassol irrigado e obter seus respectivos coeficientes de cultivo, nas diferentes fases fenológicas, para as condições edafoclimáticas de Apodi, RN.

\section{Material e Métodos}

O trabalho foi conduzido na fazenda experimental pertencente à Empresa de Pesquisa Agropecuária do Rio Grande do Norte (EMPARN) no município de Apodi, RN (latitude: $5^{\circ} 37^{\prime} 38^{\prime \prime} \mathrm{S}$; longitude: $37^{\circ} 49^{\prime} 55^{\prime}$ ' W e altitude de $150 \mathrm{~m}$ ). A região apresenta clima muito quente e semiárido, conforme a classificação climática de Köppen, com temperatura média anual de $27,1^{\circ} \mathrm{C}$, temperatura máxima média de $34,1^{\circ} \mathrm{C}$ e temperatura mínima média de $22,8{ }^{\circ} \mathrm{C}$. A insolação média da região é de $3041 \mathrm{~h}_{\text {ano }}{ }^{-1}$, com evaporação média de 2190 $\mathrm{mm}$ ano $^{-1}$, umidade relativa média de $66,8 \%$ e precipitação média de $893 \mathrm{~mm} \mathrm{ano}^{-1}$, segundo dados do Instituto Nacional de Meteorologia (Ramos et al., 2009). Quanto ao solo, a área foi classificada como Cambissolo, de textura franco-argilosa.

Uma área de 0,9 ha foi cultivada com a cultura do girassol (cultivar Catissol I) utilizando-se um espaçamento de $0,9 \mathrm{~m}$ entre fileiras e $0,25 \mathrm{~m}$ entre plantas. O preparo do solo foi realizado através de subsolagem seguida de uma gradagem com grade niveladora. O plantio foi realizado no dia 15/10/2010 e o ciclo total da cultura foi de 90 dias.

Aplicou-se uma dose de 0-60-10 kg ha-1 de N, $\mathrm{P}_{2} \mathrm{O}_{5}$ e $\mathrm{K}_{2} \mathrm{O}$, respectivamente, como adubação de fundação utilizando-se, como fonte de nutriente, o superfosfato triplo e o cloreto de potássio; já a adubação de cobertura foi efetuada 40 dias após 
a emergência aplicando-se, na ocasião, $60 \mathrm{~kg} \mathrm{ha}^{-1}$ de $\mathrm{N}$, na forma de ureia.

As irrigações foram realizadas por um sistema de aspersão, com espaçamento de $15 \times 12 \mathrm{~m}$ entre os aspersores que, segundo as especificações do fabricante, aplicam $1,8 \mathrm{~m}^{3} \mathrm{~h}^{-1}$, trabalhando a uma pressão de serviço de $250 \mathrm{kPa}$. A lâmina bruta total de água aplicada durante o ciclo da cultura foi de $465 \mathrm{~mm}$, dos quais
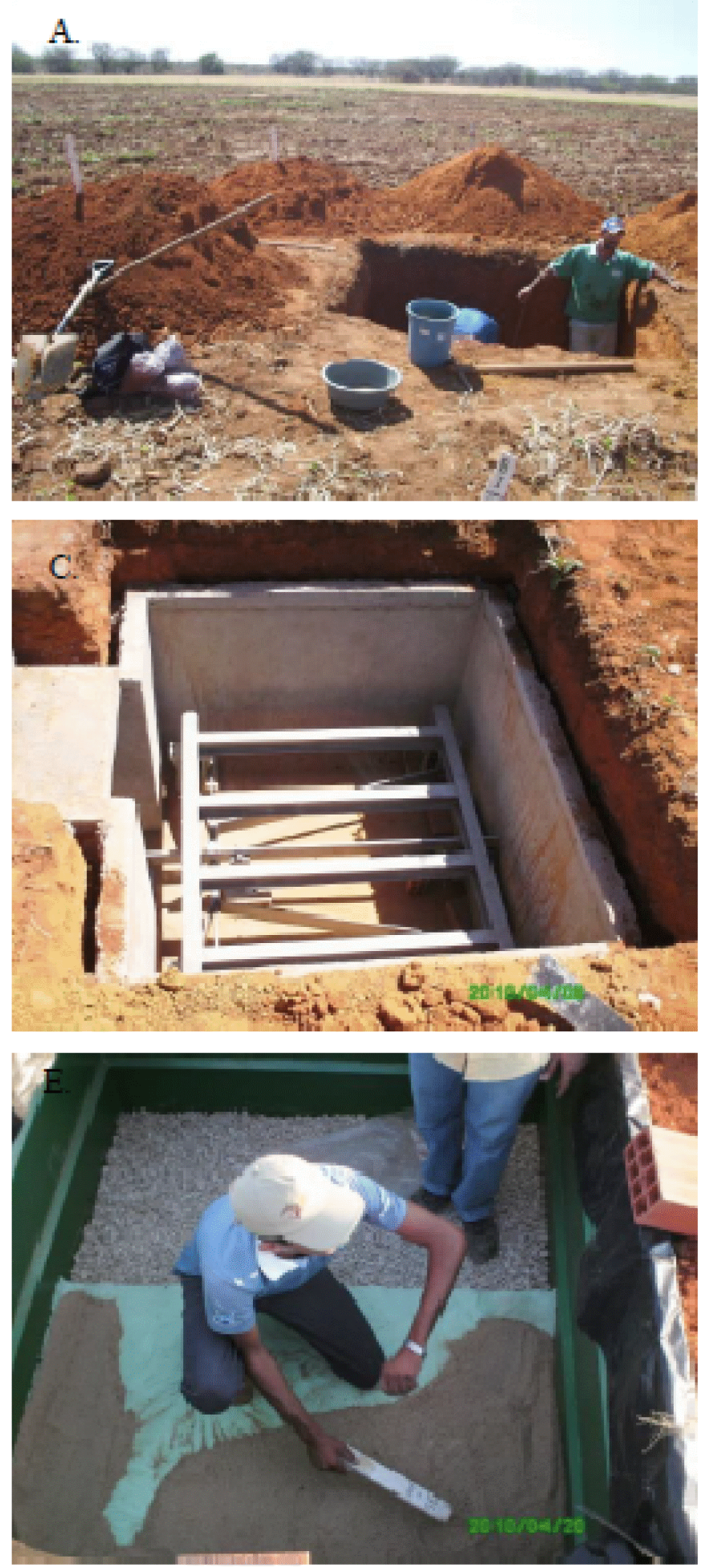

$98,0 \mathrm{~mm}$ por meio da precipitação e $367,0 \mathrm{~mm}$ via irrigação. As irrigações foram realizadas com intervalo médio de três dias.

Com vista à determinação da evapotranspiração da cultura (ETc) nos diversos estádios de desenvolvimento, utilizaramse dois lisímetros de pesagem idênticos (Lis 1 e Lis 2) que foram instalados em posições estratégicas a fim de minimizar os efeitos da advecção provocada pela área circundante do
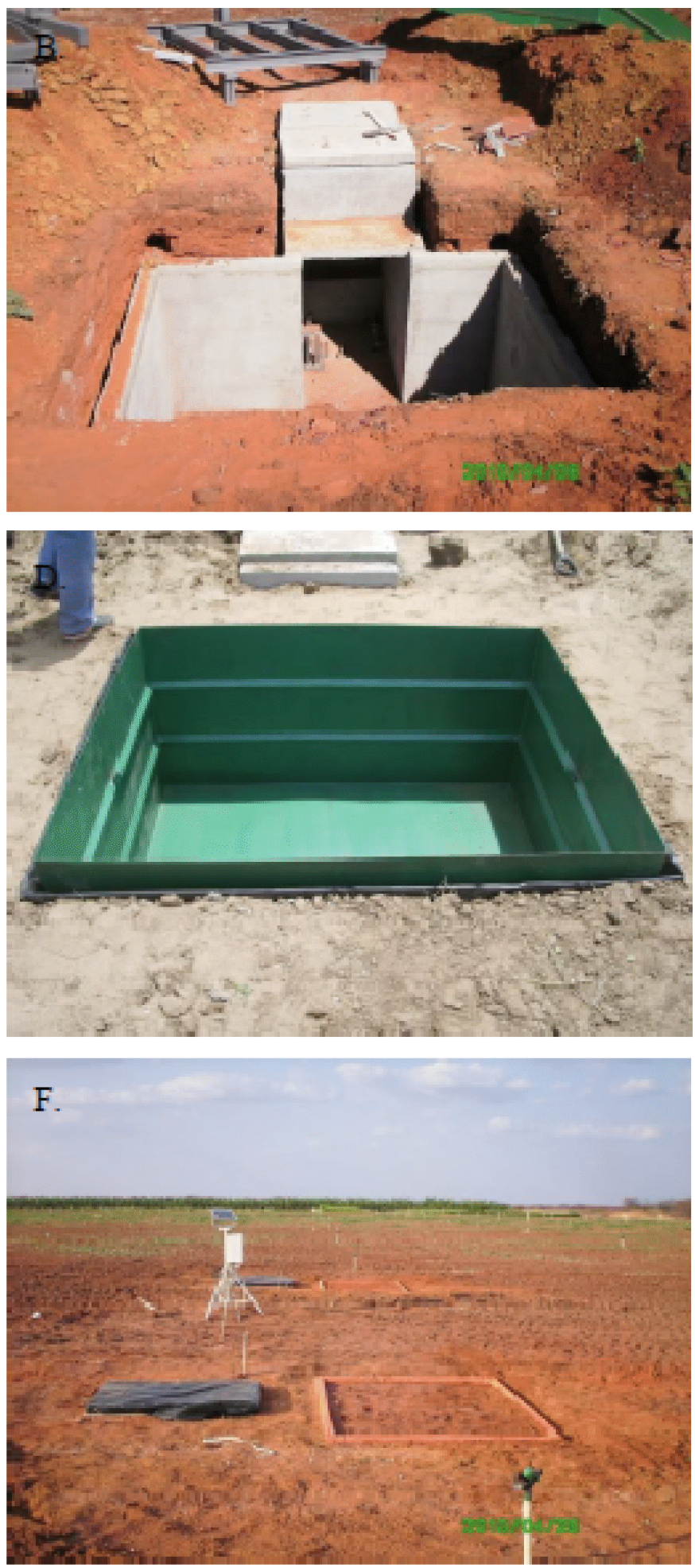

Figura 1. Sequência de instalação dos lisímetros de pesagem, (A) escavação; (B)estrutura de alvenaria; (C) balança instalada; (D) estrutura metálica;(E) preenchimento do lisímetro e (F) posicionamento dos lisímetros instalados em campo 
experimento. A Figura 1F mostra o posicionamento dos lisímetros em campo.

Os lisímetros(Figura 1D) possuem dimensões de 1,5 x 1,8 $\mathrm{m}$ de área e $0,9 \mathrm{~m}$ de profundidade útil (dimensões internas) constituídos de chapa de aço de 1/8", com uma saída para drenagem localizada no fundo da caixa. A caixa interna de aço foi posicionada sobre uma balança eletrônica de precisão que, por sua vez, estava assentada em laje de concreto com espessura de $10 \mathrm{~cm}$ (Figura 1C).

A balança possuía uma barra de pesagem (braço de apoio) ligada a um elemento sensível (célula de carga) transferindo o peso do conjunto lisimétrico à célula de carga a uma proporção de 100:1, ou seja, para uma variação de peso de $100 \mathrm{~kg}$ nos lisímetros a célula de carga registrava uma variação de $1 \mathrm{~kg}$. As células de carga utilizadas foram fabricadas pela Alfa Instrumentos modelo SV50 com capacidade de $50 \mathrm{~kg}$. As leituras das células de carga foram feitas automaticamente, por um sistema de aquisição de dados (modelo CR1000, da Campbell Scientific) programado para realizar leituras a cada $60 \mathrm{~s}$ e os dados de saída a cada $10 \mathrm{~min}$.

Os lisímetros foram preenchidos com solo da própria área, escavado em camadas de $25 \mathrm{~cm}$ de profundidade, que foram separadas em blocos e, posteriormente, recolocadas na mesma ordem em que foram retiradas mantendo, assim, a mesma sequência de horizontes do solo original (Figura 1A). Amostras de cada camada foram retiradas para determinação da densidade do solo. Antes de recolocar o solo nas caixas em suas respectivas profundidades foi colocada uma camada de $8 \mathrm{~cm}$ de brita $\mathrm{n}^{\circ} 1$ e acima da brita uma manta de poliester, com a finalidade de auxiliar na drenagem da água e evitar entupimento do orifício no fundo da caixa (Figura 1E).

Para cômputo da lâmina de água aplicada nas irrigações foi instalada, em cada lisímetro, uma bateria com cinco pluviômetros pequenos, nos quais eram realizadas as leituras, ao final das irrigações.

A calibração dos lisímetros foi realizada para posterior conversão da leitura feita pelo sistema de aquisição de dados, dada em milivolts $(\mathrm{mV})$ para massa $(\mathrm{kg})$. Para isto, realizou-se a adição unitária e sucessiva, e posterior subtração, de massaspadrão, com peso conhecido, sobre a superfície do lisímetro, efetuando-se simultaneamente as leituras correspondentes no sistema de aquisição de dados, de forma a coletar valores para aferição posterior. Os dados coletados foram submetidos à análise de regressão linear, e as massas (adicionadas/retiradas) consideradas as variáveis independentes e as leituras do sistema de aquisição de dados como as dependentes. Como as células de cargas apresentavam resolução de $0,0001 \mathrm{mV} / \mathrm{V}$, verificou-se, após as calibrações, que o lisímetro 1 trabalhou fazendo leituras a cada $0,05683 \mathrm{~kg}$ de peso adicionado ou retirado e o lisímetro 2 a cada $0,05804 \mathrm{~kg}$, no que implica dizer que os lisímetros têm resoluções de 0,02105 e 0,02150 $\mathrm{mm}$, respectivamente. Como a área do lisímetro era de 2,7 $\mathrm{m}^{2}(1,5 \times 1,8 \mathrm{~m})$ cada quilo colocado correspondeu a 0,370 mm de água.

A evapotranspiração de referência (ETo) foi estimada a partir dos dados meteorológicos obtidos em uma estação meteorológica automática, pertencente ao INMET, instalada a $300 \mathrm{~m}$ da área experimental.
De acordo com Allen et al. (2006) a equação de PenmanMonteith assume a seguinte forma para a evapotranspiração de referência:

$$
\text { ETo }=\frac{0,408 \Delta\left(\mathrm{R}_{\mathrm{n}}-\mathrm{G}\right)+\gamma \frac{900}{\mathrm{~T}_{\text {med }}+273} \mathrm{u}_{2}\left(\mathrm{e}_{\mathrm{s}}-\mathrm{e}_{\mathrm{a}}\right)}{\Delta+\gamma\left(1+0,34 \mathrm{u}_{2}\right)}
$$

em que:

$\mathrm{ET}_{\mathrm{O}}$ - evapotranspiração de referência $\left(\mathrm{mm} \mathrm{d}^{-1}\right)$

$\mathrm{Rn}$ - saldo de radiação ou Radiação líquida $\left(\mathrm{MJ} \mathrm{m}^{-2} \mathrm{~d}^{-1}\right)$

$\mathrm{G}$ - densidade de fluxo de calor no solo $\left(\mathrm{MJ} \mathrm{m}^{-2} \mathrm{~d}^{-1}\right)$

$\mathrm{T}_{\text {méd }}$ - temperatura média diária do ar a $2 \mathrm{~m}$ de altura $\left({ }^{\circ} \mathrm{C}\right)$

$\mathrm{u}_{2} \quad$ - velocidade do vento média diária a $2 \mathrm{~m}$ de altura $\left(\mathrm{m} \mathrm{s}^{-1}\right)$

$\mathrm{e}_{\mathrm{s}} \quad$ - pressão de saturação do vapor médio diário $(\mathrm{kPa})$

$\mathrm{e}_{\mathrm{a}} \quad$ - pressão atual de vapor médio diário $(\mathrm{kPa})$

$\Delta \quad$ - declividade da curva de pressão de vapor no ponto de $\mathrm{T}_{\text {méd }}\left(\mathrm{kPa}^{\circ} \mathrm{C}^{-1}\right)$

$\gamma \quad$ - coeficiente psicrométrico $\left(\mathrm{kPa}^{\circ} \mathrm{C}^{-1}\right)$

A determinação dos valores de Kc foi realizada através do quociente da $\mathrm{ET}_{\mathrm{C}} \mathrm{e}$ da $\mathrm{ET}_{\mathrm{O}}$, como representado abaixo:

$$
\mathrm{Kc}=\frac{\mathrm{ETc}}{\mathrm{ETo}}
$$

Após a obtenção dos valores de Kc em cada fase fenológica, realizou-se a comparação com os indicados pela metodologia da FAO.

Para a fase inicial o valor de Kc varia principalmente em decorrência da evaporação do solo. Portanto, para sua estimativa deve ser considerada a frequência de umedecimento da superfície durante a fase inicial. Sua estimativa foi obtida conforme procedimento abaixo (Allen et al., 2006):

$$
\mathrm{Kc}_{\text {inc }}=\frac{\mathrm{w}_{\mathrm{x}}-\left(\mathrm{w}_{\mathrm{x}}-\mathrm{w}_{1}\right) \exp \left[\frac{-\left(\mathrm{tw}-\mathrm{t}_{1}\right) \mathrm{E}_{\mathrm{SO}}\left(\frac{\mathrm{w}_{\mathrm{l}}}{\mathrm{w}_{\mathrm{x}}-\mathrm{w}_{1}}\right)}{\mathrm{w}_{\mathrm{x}}}\right]}{\operatorname{para~}_{\mathrm{w}}>\mathrm{t}_{1} \cdot \mathrm{e} ; \mathrm{Kc}_{\text {inc }}=1,15 \mathrm{t}_{\mathrm{w}}}
$$

em que:

$\mathrm{Kc}_{\text {inc }}$ - coeficiente de cultivo na fase inicial

$\mathrm{W}_{\mathrm{x}}$ - lâmina total evaporável (mm) (mm)

$\mathrm{W}_{1}$ - lâmina facilmente evaporável durante a primeira fase

$\mathrm{t}_{\mathrm{w}} \quad$ - intervalo médio entre umedecimento do solo (dias)

$t_{1} \quad$ - tempo em que o solo evapora em seu potencial máximo dependendo da quantidade de energia disponível (dias)

$\mathrm{E}_{\mathrm{SO}}$ - taxa máxima de evaporação do solo $\left(\mathrm{mm} \mathrm{d}^{-1}\right)$

ETo - evapotranspiração de referência $\left(\mathrm{mm} \mathrm{d}^{-1}\right)$

Em referência à determinação dos valores de $\mathrm{Kc}$ das fases seguintes, foi empregada a metodologia do Kc dual, apresentada por Allen et al. (2006) conforme equação abaixo: 


$$
\mathrm{Kc}=\mathrm{Ke}+\mathrm{Kb}
$$

em que:

$\mathrm{Ke}$ - coeficiente de evaporação e $\mathrm{Kb}$ o coeficiente basal da cultura.

\section{Resultados E Discussão}

Pode-se observar, nas Figuras 2, 3 e 4, a variação dos principais elementos meteorológicos durante o período de condução do experimento, tal como, também, que a temperatura média diária variou entre 24,5 e $30,1{ }^{\circ} \mathrm{C}$, com média absoluta de $28,4{ }^{\circ} \mathrm{C}$, próximo à faixa recomendada como ideal para o cultivo do girassol, em torno de 27 e $28{ }^{\circ} \mathrm{C}$ (Acosta, 2009). As temperaturas máxima e mínima absolutas registradas aos 43 e 73 dias após o plantio foram, respectivamente, de 38,1 e $21,4^{\circ} \mathrm{C}$.

No que concerne à radiação global (Figura 3 ) os totais diários oscilaram entre 8,6 e 29,2 $\mathrm{MJ} \mathrm{m}^{-2}$, sendo os valores mais baixos correspondentes a dias com ocorrência de elevada nebulosidade ou precipitações. Esta grande oscilação ocasionou uma variabilidade na ETo, durante o ciclo. A umidade relativa do ar obteve uma amplitude diária elevada durante o experimento, variando em média $52 \%$ a diferença entre a mínima e a máxima

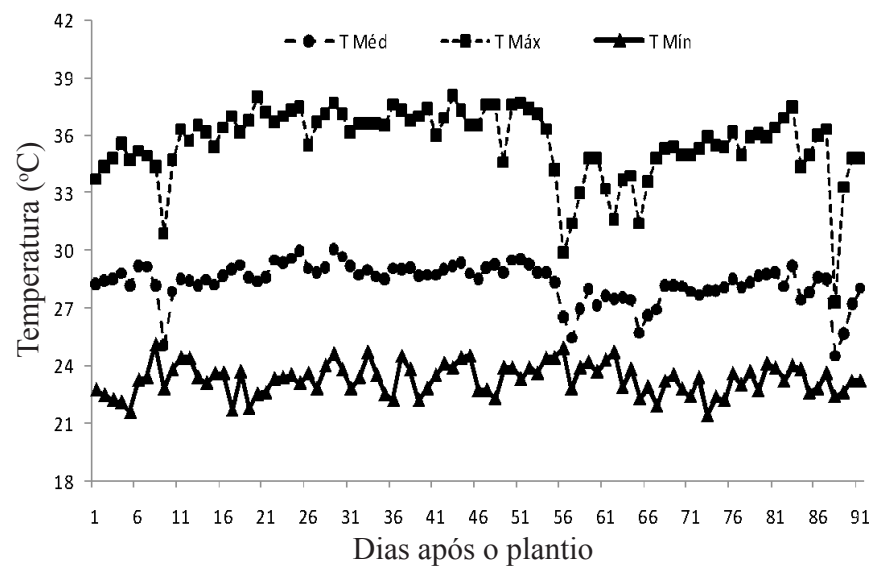

Figura 2. Valores diários de temperatura máxima (T Máx), mínima (T Mín) e média (T Méd) registrados entre 15/10/2010 e 13/01/2011

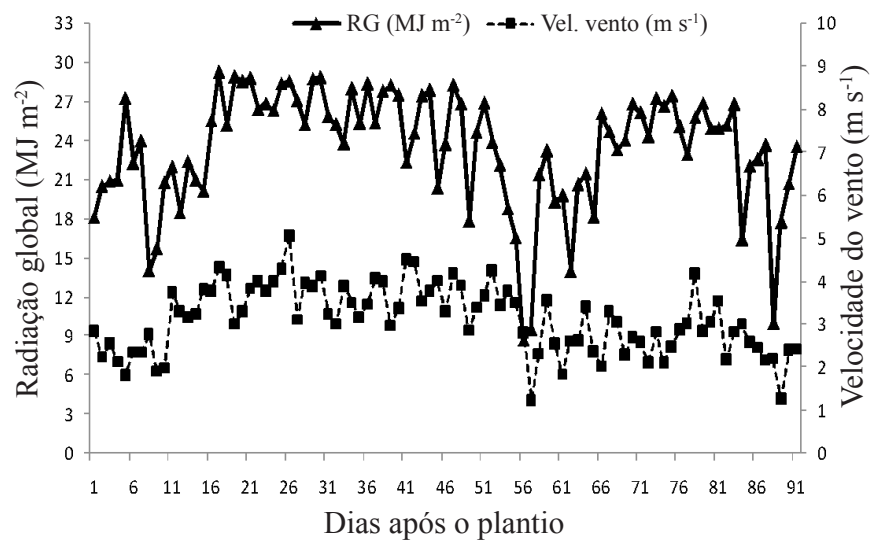

Figura 3. Total diário de radiação global (RG) e velocidade do vento média diária (Vel. vento) registrados entre 15/10/2010 e 13/01/2011

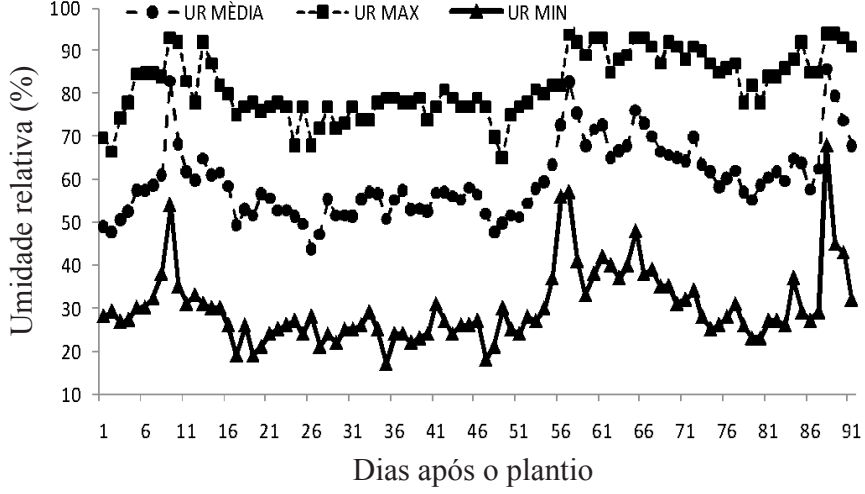

Figura 4. Valores diários da umidade relativa máxima (UR MAX), mínima (UR MIN) e média (UR MÉDIA) registrados entre 15/10/2010 e 13/01/2011

umidade diária. A umidade relativa média foi de $59 \%$, valor normal para a época na região que, segundo Ramos et al. (2009) é de $59,7 \%$. Verificou-se que aos 55 dias após o plantio (DAP) a UR cresceu e permaneceu num patamar mais alto, período em que ocorreram algumas chuvas.

Comumente, a região apresenta ocorrência de ventos fortes, com média climatológica de $3,2 \mathrm{~m} \mathrm{~s}^{-1}$ nos meses de agosto, setembro e outubro. O comportamento da velocidade média do vento durante o experimento pode ser visto na Figura 4. A velocidade do vento foi fator preponderante para altas taxas de evapotranspiração registradas. Como a região é caracterizada por um clima semiárido e principalmente com a utilização da irrigação, aconteceram elevadas taxas de evaporação e transpiração. O vento tende a remover a camada de ar úmido logo acima da vegetação e substituí-la por uma camada de ar geralmente mais seca, o que proporciona o surgimento de um elevado gradiente de pressão de vapor aumentando, então, a capacidade de evaporação.

A Figura 5 apresenta a variação da ETo estimada, da $\mathrm{ET}_{\mathrm{C}}$ medida e da $\mathrm{ET}_{\mathrm{C}}$ estimada com o Kc dual. Ao longo do ciclo a ETo demonstrou grande variabilidade com valor máximo chegando a $8,67 \mathrm{~mm} \mathrm{~d}^{-1}$ e o mínimo de 2,36 $\mathrm{mm} \mathrm{d}^{-1}$. No final do experimento constatou-se que a ETc total foi de $442 \mathrm{~mm}$, valor este inferior ao obtido por Acosta (2009) que contabilizou o total

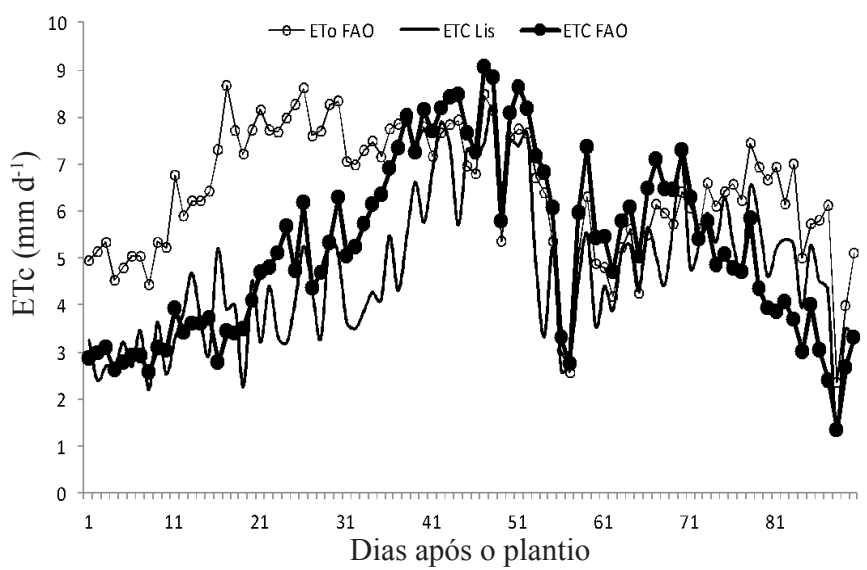

Figura 5. Variação da evapotranspiração da cultura medida (ETc Lis), estimada (ETc FAO) e da evapotranspiração de referência (ETo FAO) observada durante o ciclo do girassol 
de 554,1 mm para a mesma cultivar e na mesma região, porém em época de semeadura diferente da utilizada neste trabalho. Silva et al. (2007) avaliaram a aplicação de diferentes lâminas de irrigação na cultura do girassol, na região de Lavras, $\mathrm{MG}$, e verificaram que a lâmina total evapotranspirada durante todo o ciclo foi de $311,5 \mathrm{~mm}$, valor inferior ao encontrado neste trabalho, em virtude principalmente das regiões apresentarem climas distintos, em que a região de Lavras, $\mathrm{MG}$, apresenta um clima mais ameno e, em contrapartida, uma demanda evaporativa atmosférica menor.

Para as fases inicial de desenvolvimento vegetativo, de floração e final, os coeficientes de cultivo apresentados na Tabela 1 foram calculados como sendo os médios durante as fases. Os coeficientes de cultivo determinados neste estudo foram inferiores aos recomendados pela FAO (Allen et al., 2006) para todas as fases, com exceção da fase final, fase para a qual o indicado seria utilizar o valor do Kc na data da colheita, em que se espera que a senescência das plantas e o corte da irrigação, aos $84 \mathrm{DAP}$, gerem uma redução gradativa no seu valor mas a ocorrência de precipitações nos quatro dias anteriores à colheita resultou numa elevação no valor do Kc, principalmente em virtude da alta taxa de evaporação da água do solo.

Tabela 1. Duração das fases fenológicas e coeficiente de cultivo médio $(\mathrm{Kc})$ do girassol, cultivar Catissol I

\begin{tabular}{lccccc}
\hline \multirow{2}{*}{ Fase } & Duração & \multicolumn{4}{c}{ Coeficiente de cultivo } \\
\cline { 3 - 6 } & (dias) & Lis 1 & Lis 2 & Lis & FA0 \\
I - Inicial & 28 & 0,54 & 0,50 & 0,52 & 0,60 \\
II - D. vegetativo & 15 & 0,78 & 0,70 & 0,74 & 0,95 \\
III - Floração & 27 & 1,01 & 0,95 & 0,98 & 1,09 \\
IV - M. fisiológica & 20 & 0,82 & 0,79 & 0,81 & 0,69 \\
\hline
\end{tabular}

Na Figura 6 são apresentadas as curvas dos valores médios de $\mathrm{Kc}$, ao longo do ciclo da cultura, determinadas neste estudo. Os valores médios de $0,52,0,74,0,98$ e 0,81 obtidos nas fases I, II, III e IV respectivamente (Tabela 1) diferiram um pouco dos obtidos por Acosta (2009) para a mesma cultivar e trabalhando na mesma região com a utilização da metodologia do balanço de energia, o que explica as diferenças nos valores de Kc tendo em vista que os métodos se baseiam em princípios distintos do cômputo da ETc.

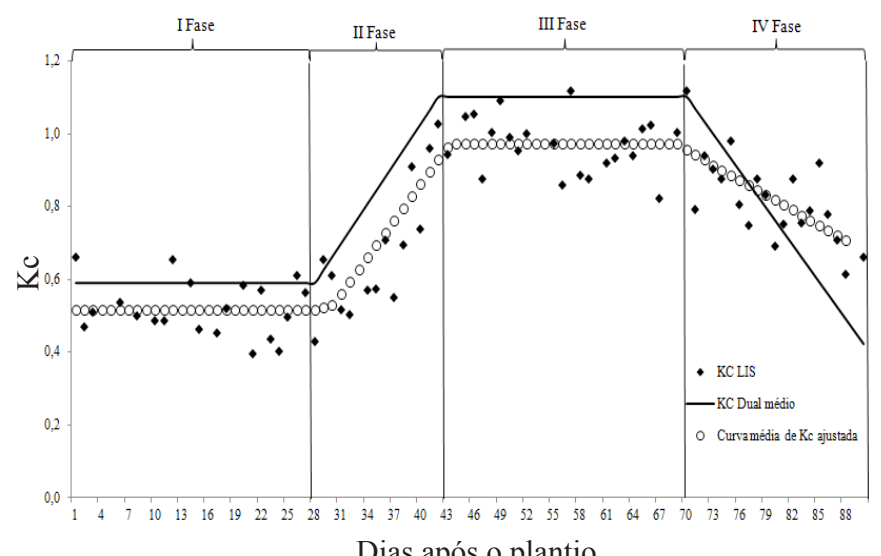

Figura 6. Variação do coeficiente de cultivo (Kc) observada durante o ciclo vegetativo do girassol

\section{Conclusões}

1. A evapotranspiração total da cultura (ETc) do girassol é de $442 \mathrm{~mm}$ com ciclo de 90 dias, valor médio diário de 4,9 $\mathrm{mm}$ e valor máximo chegando a $8,18 \mathrm{~mm}$, obtido na fase de floração.

2. Os coeficientes de cultivo variaram de 0,$52 ; 0,74 ; 0,98 \mathrm{e}$ 0,81 para as diferentes fases fenológicas da cultura do girassol, que tiveram duração de $28,15,27$ e 20 dias, respectivamente, para a cultivar Catissol I nas condições edafoclimáticas de Apodi, RN.

\section{Agradecimentos}

Ao Conselho Nacional de Desenvolvimento Científico e Tecnológico $(\mathrm{CNPq})$ pelo financiamento da bolsa de estudo do primeiro autor.

\section{Literatura Citada}

Acosta, J. F. Consumo hídrico da cultura do girassol irrigada na região da chapada do Apodi - RN. Campina Grande: UFPB,2009. 56P.Dissertação Mestrado

Allen, R. G.; Pereira, L. S.; Raes, D.; Smith. Evapotranspiration del cultivo: Guias para la determinación de los requerimientos de agua de los cultivos. Rome: FAO, 2006. 298p. FAO, Estudio Riego e Drenaje Paper, 56

Doorenbos, J.; Pruitt, W. O. Guidelines for predicting crop water requirements. 2.ed. Rome: FAO, 1977. 179p. Irrigation and Drainage Paper, 24

Figueirêdo, V. B.; Medeiros, J. F.; Zocoler, J. L.; Espinola Sobrinho, J. Evapotranspiração da cultura da melancia irrigada com água de diferentes salinidades. Engenharia Agrícola, v.29, p.231-240, 2009.

Howell, T. A.; Mccormick, R. L.; Phene, C. J. Design and instalation of large weighing lysimeters. Transactions of the ASAE, v.28, p.106-112, 1985.

Leite, R. M. V. B. de C.; Castro, C. de; Brighenti, A. M.; Oliveira, F. A. de; Carvalho, C. G. P. de; Oliveira, A. C. B. de. Indicações para o cultivo do girassol nos estados do Rio Grande do Sul, Paraná, Mato Grosso do Sul, Mato Grosso, Goiás e Roraima . Londrina: Embrapa Soja, 2007. 4p. Comunicado Técnico, 78

Loos, C.; Gayler, S.; Priesack, E. Assessment of water balance simulations for large-scale weighing lysimeters. Journal of Hydrology, v.335, p.259-270, 2007.

López-Urrea, R.; Olalla, F. M. S.; Fabeiro, C.; Moratalla, A. Testing evapotranspiration equations using lysimeter observations in a semiarid climate. Agricultural Water Management, v.85, p.15-26, 2006.

Miranda, F. Rodriguez de; Oliveira, J. J. G.; Souza, F. de. Evapotranspiração máxima e coeficiente de cultivo para a cultura da melancia irrigada por gotejamento. Revista Ciência Agronômica, v.35, p.36-43, 2004.

Morais, F. A,; Gurgel, M. T.; Oliveira, F. H. T.; Mota, A. F. Influência da irrigação com água salina na cultura do girassol. Revista Ciência Agronômica, v.42, p.327-336, 2011. 
Pereira, A. R.; Santiago, A. V.; Maggioto, S. R.; Folegatti, M. V. Problemas operacionais com lisímetros de pesagem durante a estação chuvosa e em dias secos com rajadas de vento. Revista Brasileira de Agrometeorologia, v.10, p.51-6, 2002.

Pereira, L, S.; Allen, R. G. Novas aproximações aos coeficientes de culturais. Engenharia Agrícola, v.16, p.118-143, 1997.

Ramos, A. M.; Santos, L. A. R.; Fortes, L. T. G. Normais climatológicas do Brasil 1961-1990. Brasília: Instituto Nacional de Meteorologia. 2009. 465p.

Silva, F. C.; Folegatti, M. V.; Maggiotto, S. R. Análise do funcionamento de um lisímetro de pesagem com célula de carga. Revista Brasileira de Agrometeorologia, v.7, p.5358, 1999.
Silva, L. D. B.; Folegatti, M. V.; Villa Nova, N. A. Evapotranspiração do capim Tanzânia obtida pelo método de razão de Bowen e lisímetro de pesagem. Engenharia Agrícola, v.25, p.705-712, 2005.

Silva, M. L. O.; Faria, M. A.; Morais, A. R.; Andrade, G. P.; Lima, E. M. Crescimento e produtividade do girassol cultivado na entressafra com diferentes lâminas de água. Revista Brasileira de Engenharia Agrícola e Ambiental. v.11, p.482-488, 2007.

Vaughan, P. J.; Trout, T. J.; Ayars, J. E. A processing method for weighing lysimeter data and comparison to micrometeorological ETo predictions. Agricultural Water Management, v.88, p.141-146, 2007. 